\title{
Pseudoaneurisma y fístula arteriovenosa ilíaca post cirugía de disco intervertebral lumbar*
}

\author{
Drs. JUAN BOMBIN F. ${ }^{1}$, ALEJANDRO KOTLIK A. ${ }^{1}$, SERGIO PACHECO S. ${ }^{2}$, \\ CARLA PIZARRO S. ${ }^{1}$, JAIME FERNÁNDEZ V. ${ }^{1}$, TM. IVER ZEGARRA I. ${ }^{3}$ \\ Servicio de Cirugía, Hospital Dr. Eduardo Pereira, Universidad de Valparaíso. \\ 2 Residente de Cirugía General, Universidad de Valparaíso. \\ 3 Hospital Dr. Eduardo Pereira. \\ Valparaíso, Chile.
}

\section{Iliac pseudoaneurysm and arteriovenous fistula after surgery for lumbar intervertebral disc}

Paciente de sexo femenino de 46 años con cuadro de 1 año de evolución de dolor lumbar irradiado a extremidad inferior derecha, que fue estudiada en el policlínico de neurocirugía con resonancia nuclear magnética de columna que demostró hernia al núcleo pulposo L4-L5 derecha. Debido a esto se realizó disectomía lumbar sin reportar complicaciones intraoperatorias. A las $6 \mathrm{~h}$ del postoperatorio cursa con dolor abdominal intenso, vómitos e hipotensión que respondió a volemización, se realizó angioTC que mostró pseudoaneurisma y fístula arteriovenosa de arteria ilíaca común izquierda (Figuras 1 y 2). Se realizó angiografía que confirmó hallazgos y se procedió a la colocación de stent cubierto Fluency Plus de BARD de $10 \mathrm{~mm}$ x $60 \mathrm{~mm}$ (Figura 3). La paciente evolucionó favorablemente siendo dada de alta al día siguiente. Tras 5 meses de la cirugía la paciente no ha presentado complicaciones, con angioTC de control que mostró stent in situ (Figura 4). Este tipo de lesiones son de baja frecuencia reportándose en 1 a 5 casos por cada diez mil disectomías ${ }^{1,2}$. Se deben sospechar ante la presencia de dolor abdominal, sangrado inexplicable en el espacio intervertebral e hipotensión durante o posterior a la disectomía lumbar ${ }^{3}$.

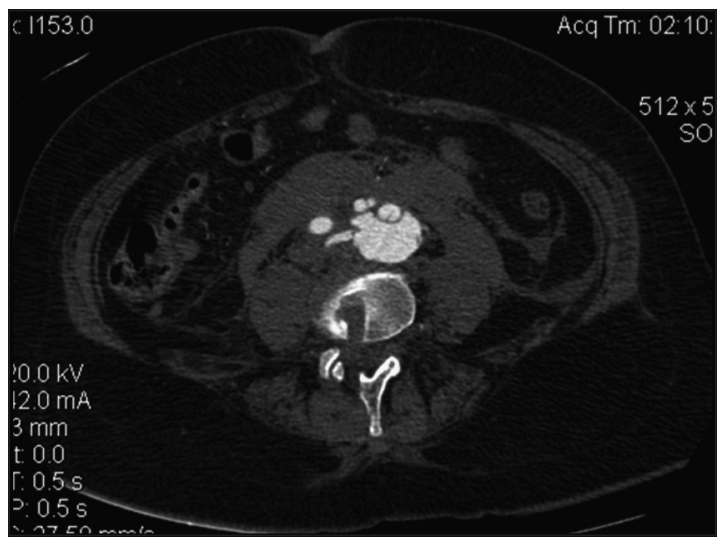

Figura 1. Corte transversal de AngioTAC que muestra pseudoaneurisma de arteria iliaca común izquierda con comunicación hacia la vena ilíaca común ipsilateral, destaca la presencia de medio de contraste ambas venas ilíacas. Además se aprecian cambios postquirúrgicos en vértebra lumbar.

*Recibido el 28 de mayo de 2012 y aceptado para publicación el 2 de julio de 2012.

Los autores no refieren conflictos de interés.

Correspondencia: Dr. Sergio Pacheco S.

Independencia 2838 depto 33, Valparaíso, Chile.

sergiopacheco13@gmail.com 


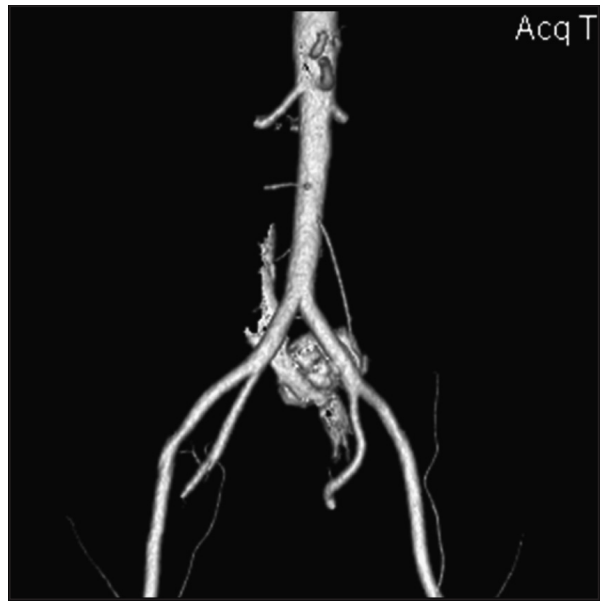

Figura 2. Reconstrucción tridimensional de AngioTC que muestra pseudoaneurisma en relación a arteria ilíaca común izquierda y fístula arteriovenosa con la vena ilíaca común.

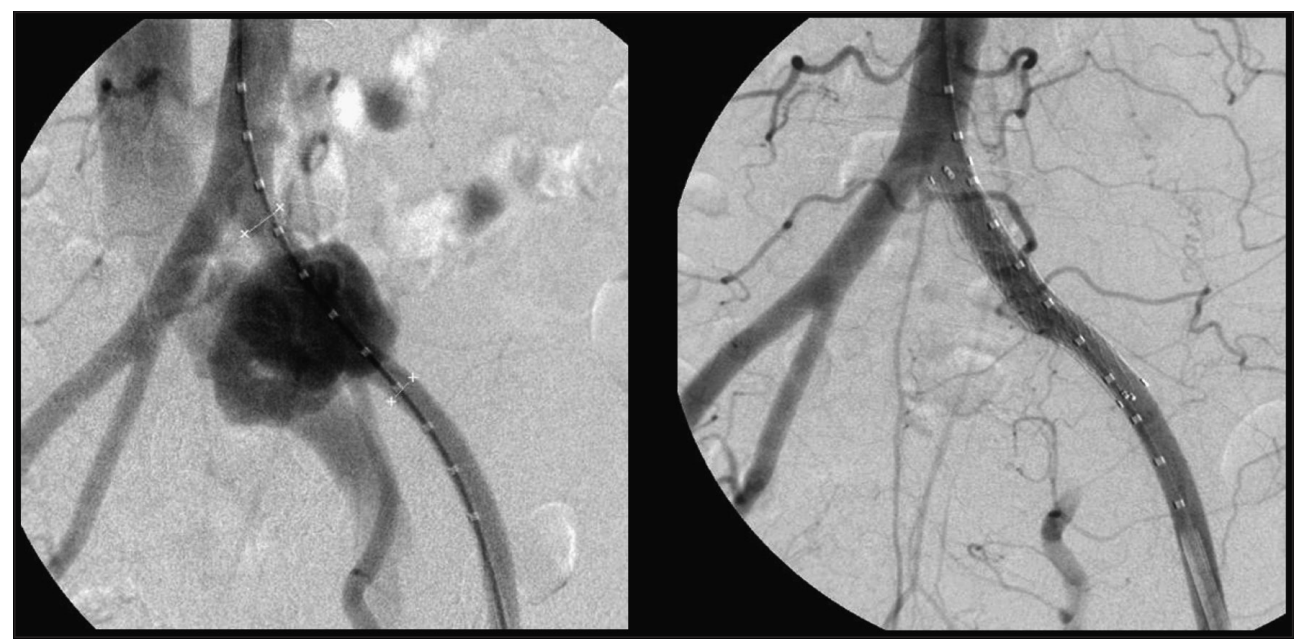

Figura 3. Arteriografía confirma pseudoaneurisma de arteria ilíaca común izquierda y paso de medio de contraste a vena ilíaca común. Tras colocación de endoprótesis cubierta la arteriografía muestra buen llene del medio de contraste hacia distal y ausencia de medio de contraste en pseudoaneurisma y en venas. Se ocluye la arteria hipogástrica la cual se reconstituye hacia distal por colaterales.

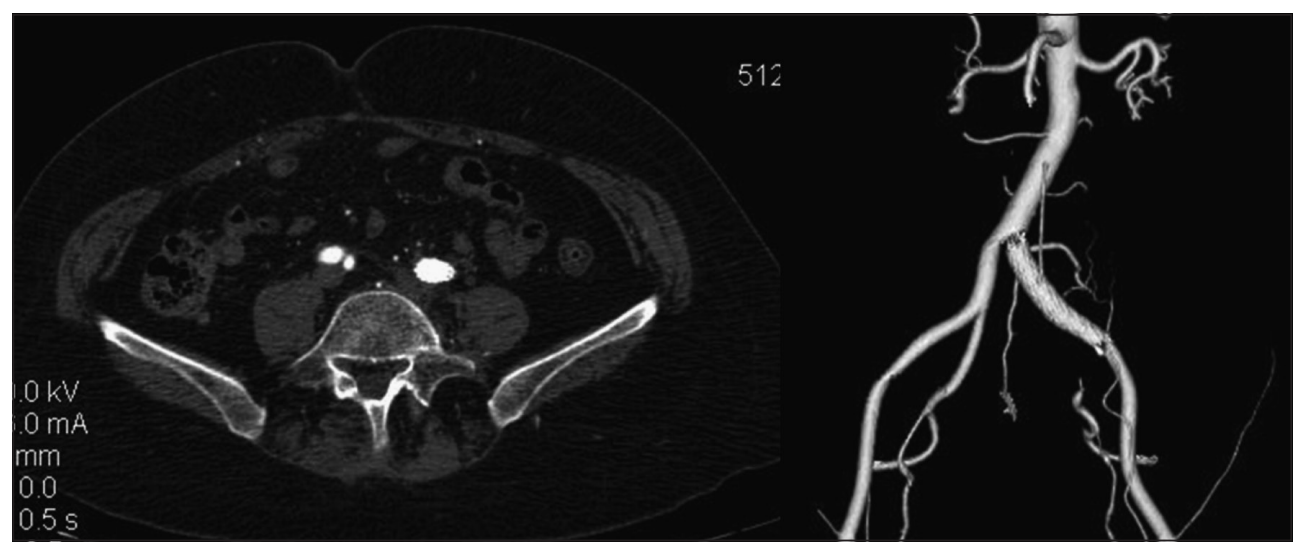

Figura 4. Tras 5 meses de realizada la intervención quirúrgica se realiza angioTC de control que muestra stent in situ sin lesiones asociadas. 
J. BOMBIN F. y col.

\section{Referencias}

1. Papadoulas S, Konstantinou D, Kourea HP, Kritikos N, Haftouras N, Tsolakis JA. Vascular injury complicating lumbar disc surgery. A systematic review. Eur J Vasc Endovasc Surg. 2002;24:189-95.

2. Herskovic J, Contreras-Levicoy JA, Díaz CP, Vidal-
Faune A, Ayala F, Campos A. Fístula arteriovenosa ilíaca, ¿postcolecistectomía o cirugía de disco intervertebral?: reporte de un caso. Rev Chil Cir. 2004;56:3925 .

3. Torun F, Tuna H, Deda H. Abdominal vascular injury during lumbar disc surgery: report of three cases. Ulus Travma Acil Cerrahi Derg. 2007;13:165-7. 